\title{
Green/Gray Tiger Top Plasma Separation Tube
}

National Cancer Institute

\section{Source}

National Cancer Institute. Green/Gray Tiger Top Plasma Separation Tube. NCI

Thesaurus. Code C129964.

A blood collection tube with lithium heparin and a gel, used for plasma determinations in chemistry. 